\title{
Building complex carbon skeletons with ethynyl[2.2]paracyclophanes
}

Ina Dix ${ }^{1}$, Lidija Bondarenko ${ }^{1}$, Peter G. Jones ${ }^{2}$, Thomas Oeser ${ }^{3}$ and Henning Hopf ${ }^{\star 1}$

\author{
Full Research Paper \\ Address: \\ ${ }^{1}$ Institut für Organische Chemie, Technische Universität \\ Braunschweig, Hagenring 30, D-38106 Braunschweig, Germany, Fax: \\ (+49)531-391-5388, ${ }^{2}$ Institut für Anorganische und Analytische \\ Chemie, Technische Universität Braunschweig, Postfach 3329, \\ D-38106 Braunschweig, Germany and ${ }^{3}$ Organisch-Chemisches \\ Institut der Universität Heidelberg Im Neuenheimer Feld 270, D-69120 \\ Heidelberg, Germany, Fax: (+49) 6221-544205 \\ Email: \\ Peter G. Jones - p.jones@tu-bs.de; Thomas Oeser - \\ thomas.oeser@oci.uni-heidelberg.de; Henning Hopf* - \\ h.hopf@tu-bs.de \\ * Corresponding author \\ Keywords: \\ carbon-rich molecules; complex carbon scaffolds; cyclophanes; \\ Glaser coupling; multibridged cyclophanes; X-ray analysis \\ Beilstein J. Org. Chem. 2014, 10, 2013-2020.
doi:10.3762/bjoc.10.209 \\ Received: 11 April 2014 \\ Accepted: 12 August 2014 \\ Published: 27 August 2014 \\ Cyclophanes, Part 70. - For Part 69, see [1]. \\ Associate Editor: H. Ritter \\ C) 2014 Dix et al; licensee Beilstein-Institut. \\ License and terms: see end of document.
}

\begin{abstract}
Ethynyl[2.2]paracyclophanes are shown to be useful substrates for the preparation of complex, highly unsaturated carbon frameworks. Thus both the pseudo-geminal- $\mathbf{2}$ and the pseudo-ortho-diethynylcyclophane $\mathbf{4}$ can be dimerized by Glaser coupling to the respective dimers $\mathbf{9} / \mathbf{1 0}$ and $\mathbf{1 1} / \mathbf{1 2}$. Whereas the former isomer pair could not be separated so far, the latter provided the pure diastereomers after extensive column chromatography/recrystallization. Isomer $\mathbf{1 1}$ is chiral and could be separated on a column impregnated with cellulose tris(3,5-dimethylphenyl)carbamate. The bridge-extended cyclophane precursor 18 furnished the ringenlarged cyclophanes 19 and 20 on Glaser-Hay coupling. Cross-coupling of $\mathbf{4}$ and the planar building block 1,2-diethynylbenzene (1) yielded the chiral hetero dimer $\mathbf{2 2}$ as the main product. An attempt to prepare the biphenylenophane $\mathbf{2 7}$ from the triacetylene $\mathbf{2 4}$ by $\mathrm{CpCo}(\mathrm{CO})_{2}$-catalyzed cycloisomerization resulted in the formation of the cyclobutadiene Co-complex $\mathbf{2 6}$. Besides by their usual spectroscopic and analytical data, the new cyclophanes 11, 12, 19, 20, 22, and 26 were characterized by X-ray structural analysis.
\end{abstract}

\section{Introduction}

Several years ago we described the preparation of various ethynyl[2.2]paracyclophanes and suggested that these compounds could be developed into useful building blocks for the construction of larger, stereochemically complex carbon frame- works (scaffolds) [2]. This prediction is clearly becoming reality, as shown by the growing use of ethynylcyclophanes as substrates for the preparation of carbon-rich organic compounds [3-6]. 
The use of ethynylaromatics for the synthesis of "extended aromatic compounds" is anything but new, as indicated by three of the smallest building blocks applied for this purpose: 1,2- (1), 1,3-(3), and 1,4-diethynylbenzene (5) (Scheme 1).

These simple, flat molecules have been used extensively for the deliberate construction of larger polyaromatic hydrocarbons employing classical (e.g., Glaser coupling and its variants) or modern acetylenic coupling reactions (e.g., the Sonogashira coupling) [7]. For the smaller oligomers (dimers, trimers) the ortho-isomer with its opening angle of $60^{\circ}$ between the ethynyl functions leads preferentially to (mono)cyclic hydrocarbons. For the meta-compound $\mathbf{3}$ we can expect both cyclic and acyclic (linear) products, and when the two ethynyl moieties are anchored in para-position, $\mathbf{5}$, the lower oligomers can no longer be cyclic because they would be too highly strained.

When two ethynyl groups are placed into the benzene rings of [2.2]paracyclophane, the situation changes. In a strict sense the analog of 1,2-diethynylbenzene (1) is 4,5-diethynyl[2.2]paracyclophane, i.e., the hydrocarbon with two ethynyl groups in vicinal position in the same ring [2,3]. If, however, our target molecules are to have the two triple bonds in different benzene rings, the pseudo-gem-diethynyl[2.2]paracyclophane $\mathbf{2}$ is the analog of 1 (Scheme 1). Analogously, phane hydrocarbons 4 and $\mathbf{6}$ correspond to $\mathbf{3}$ and $\mathbf{5}$. Clearly, in all cases employing $\mathbf{2}$, $\mathbf{4}$, and $\mathbf{6}$ as building blocks, the final structures will be layered.

We have already used the pseudo-ortho-isomer 4 in two cases describing the preparation and structural properties of the (chiral) tetraynes 7 and 8 (Scheme 2) [8].

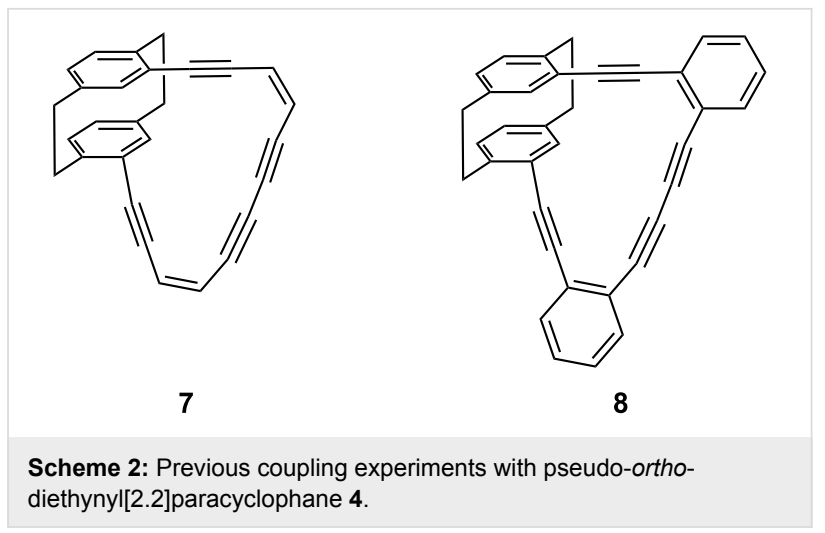

In the present contribution we have extended these studies, employing 2 and 4 as building blocks. The chemistry of $[m . n]$ paracyclophanes with (completely or partially) unsaturated molecular bridges has been poorly investigated, leaving much scope for further studies.

\section{Results and Discussion}

The oxidative dimerization (Glaser coupling) of the achiral hydrocarbon 2 took place effortlessly and in high yield (Scheme 3).

However, we have been unable so far to determine the exact structure of the isolated dimer. As shown in Scheme 3, in principle, two different dimers of $\mathbf{2}$ could be formed: one in which the ethano bridges are arranged in a parallel fashion (9), and another one in which they point towards each other ("roof" isomer 10). We could not separate the two diastereomers chromatographically (neither by hplc or tlc) so far, nor do the proton

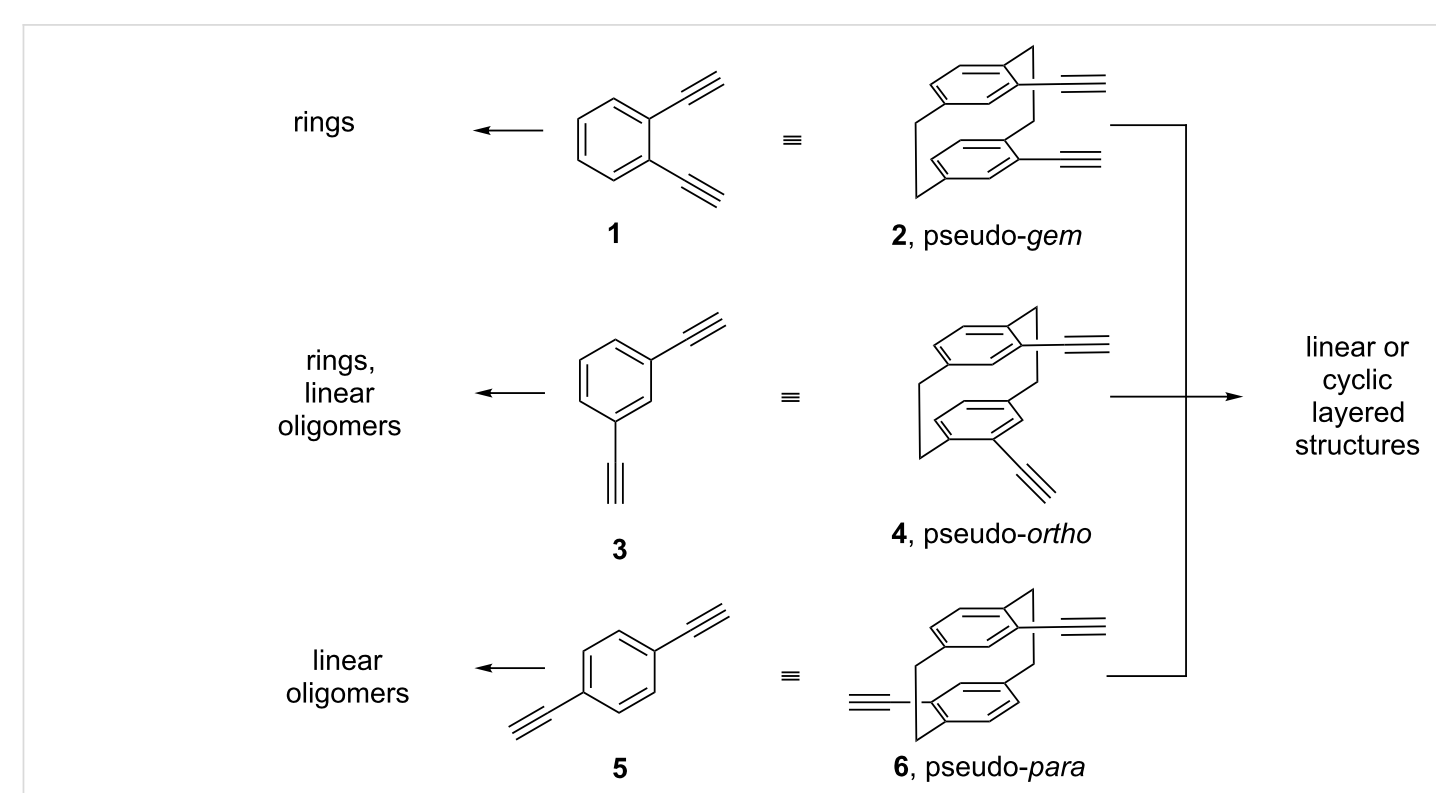

Scheme 1: Planar and layered ethynyl aromatics as building blocks for extended aromatic structures. 


\section{$2 \underset{\mathrm{CuCl}, \mathrm{TMEDA}}{\stackrel{\mathrm{air}, \mathrm{CH}_{2} \mathrm{Cl}_{2}, 20^{\circ} \mathrm{C}}{\longrightarrow}}$}

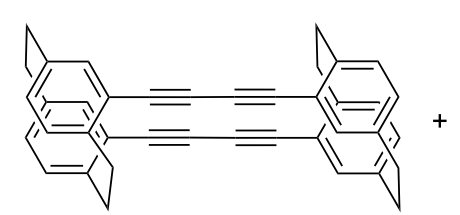

9 ("parallel")

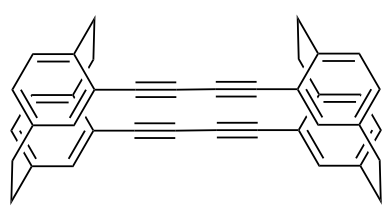

10 ("roof")

$9+10: 80-90 \%$

Scheme 3: Glaser coupling of pseudo-gem-diethynyl[2.2]paracyclophane 2.

and carbon spectra provide conclusive structural information. Our proposal of two types of dimers results, firstly, from the spectra of the dimers generated by Glaser coupling of 4-ethynyl[2.2]paracyclophane and secondly, from the dimerization results with the pseudo-ortho compound $\mathbf{4}$ described below. NMR analysis proved unambiguously that two diastereomers are generated (as expected) by the oxidative dimerization of the mono ethynyl derivative [9], but assignment of the various spectra to specific stereoisomers remains an open question, and will only be possible after the resolution of the 4-ethynyl[2.2]paracyclophane, determination of its absolute configuration, and oxidative dimerization of an enantiopure sample.

Glaser coupling of racemic $\mathbf{4}$ at room temperature yielded a mixture of diastereomeric dimers in good yield (67\%) under the conditions shown in Scheme 4. Their gross structures follow from the spectroscopic and analytical data summarized in the Supporting Information File 1.

The two very poorly soluble hydrocarbons were separated by extensive column chromatography which - albeit in poor yield - finally furnished the analytically pure dimers $\mathbf{1 1}$ and $\mathbf{1 2}$, the former eluting more rapidly from the chromatography column. Both samples could be recrystallized to provide single crystals suitable for X-ray structural analysis. Figure 1 shows that dimer 11 indeed possesses the "crossed" structure; it crystallizes with imposed twofold symmetry, but the effective (non-crystallographic) symmetry is the unusual $D_{2}(222)$ with r.m.s. deviation $0.01 \AA$.

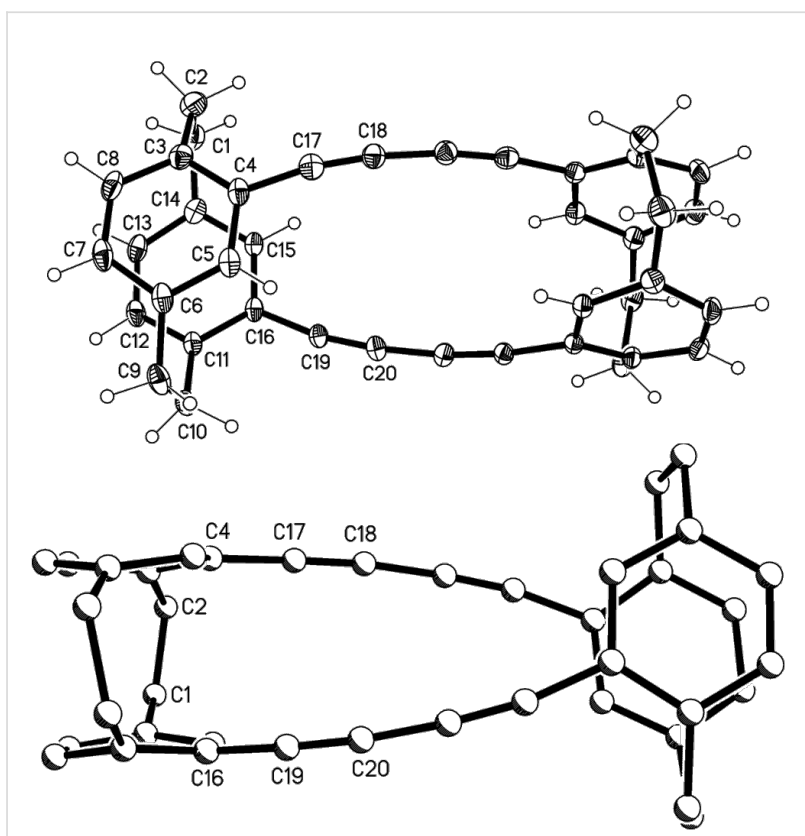

Figure 1: Above: The molecule of compound 11 in the crystal; ellipsoids represent $30 \%$ probability levels. Only the asymmetric unit is numbered. Below: Alternative view direction (arbitrary radii, without $\mathrm{H}$ atoms) showing the "crossed" geometry via the additional bridges.

Despite the extra diacetylene bridges, compound 11 preserves the general structural features of [2.2]paracyclophanes, which are strained molecules. We have discussed these in detail in our previous paper [1], and summarize them here as follows: the single bonds in the bridges, $\mathrm{C} 1-\mathrm{C} 2$ and $\mathrm{C} 9-\mathrm{C} 10$, are elongated and the $\mathrm{sp}^{3}$ angles at these atoms widened; the $\mathrm{sp}^{2}$ angles at the

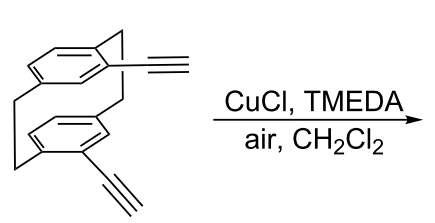

4

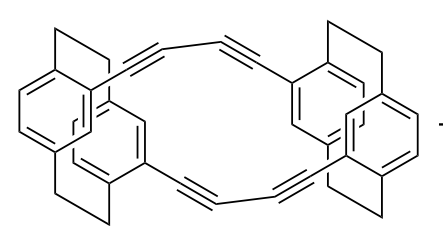

11 ("crossed")

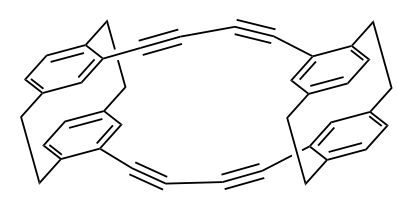

12 ("parallel") 
bridgehead atoms $\mathrm{C} 3, \mathrm{C} 6, \mathrm{C} 11$ and $\mathrm{C} 14$ are narrowed; the rings display a flattened boat conformation in which the bridgehead atoms lie ca. $0.12-0.16 \AA$ out of the plane of the other four atoms; these planes are approximately parallel to each other, as are the vectors between the bridgehead atoms, and the nonbonded contacts between bridgehead atoms are necessarily short (2.7-2.8 $\AA$ ) [4]. One slight exception for 11 is the twist of $5.7^{\circ}$ between $\mathrm{C} 3 \cdots \mathrm{C} 6$ and $\mathrm{C} 11 \cdots \mathrm{C} 14$. The extra acetylenic bridges have little or no clamping effect, with non-bonded distances $\mathrm{C} 4 \cdots \mathrm{C} 15$ and $\mathrm{C} 5 \cdots \mathrm{C} 16$ of ca. $3.07 \AA$ (this is also the case for the other "double paracyclophane" structures presented here (see below) and will not be mentioned again explicitly). The slight bowing of the extra bridges, with angles at the sp carbon of $170-173^{\circ}$, can be recognized in the Figure; we regard this angle as a "soft" parameter [1]. The angle between the two halves of the molecule, expressed as the interplanar angle between the plane of $\mathrm{C} 4, \mathrm{C} 5, \mathrm{C} 7, \mathrm{C} 8$ and its symmetry-equivalent, is $77^{\circ}$, and this is clearly imposed by the "crossed" bridge geometry.

Isomer 11, a chiral compound, was resolved into its enantiomers on a OD-column impregnated with cellulose tris(3,5dimethylphenyl) carbamate using hexane/propan-2-ol (9:1) as an eluent and a UV-detector set at $254 \mathrm{~nm}$. A baseline separation was achieved and the two enantiomers had $[\alpha]_{\mathrm{D}}{ }^{25}=-44$ ${ }^{\circ}\left(c 0.375\right.$, hexane/propan-2-ol, 9:1) and $[\alpha]_{\mathrm{D}}{ }^{25}=43^{\circ}(c 0.533$, hexane/propan-2-ol, 9:1).

The later eluting dimer is the "parallel" hydrocarbon 12 (Figure 2). This compound (Figure 2) crystallizes with imposed inversion symmetry (and is thus achiral), but the effective symmetry is $C_{2 \mathrm{~h}}(2 / m)$ with r.m.s.d. $0.14 \AA$.

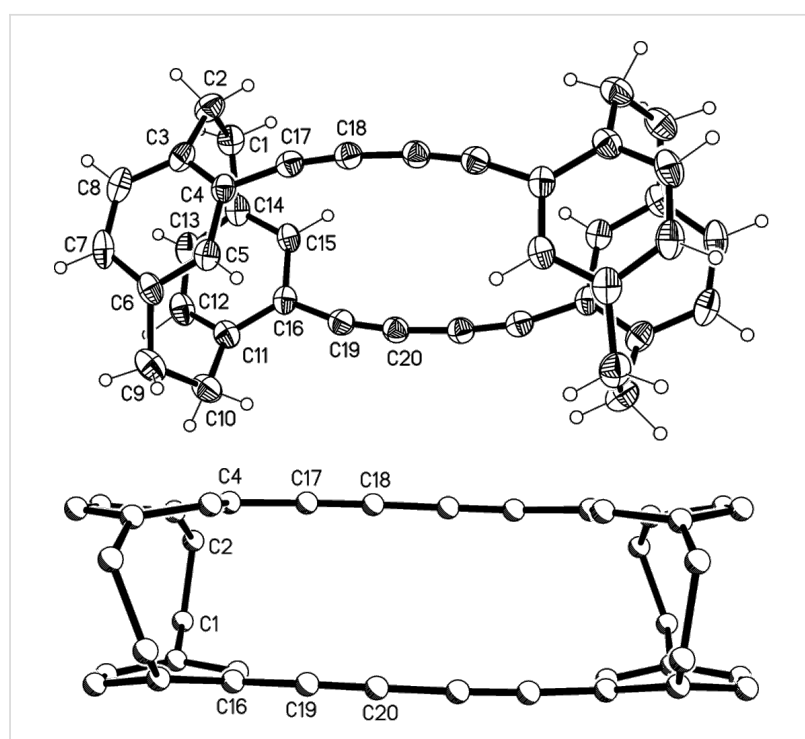

Figure 2: Above: The molecule of compound 12 in the crystal; ellipsoids represent $50 \%$ probability levels. Only the asymmetric unit is numbered. Below: Alternative view direction (arbitrary radii, without $\mathrm{H}$ atoms) showing the "parallel" geometry via the additional bridges.

Compound 12 displays the "parallel" geometry of the extra bridges, and the two paracyclophane units are indeed exactly parallel to each other by symmetry. The cyclophane rings of the asymmetric unit are twisted by $8.4^{\circ}$. The extra bridges are again bowed, and the angles depart slightly more from $180^{\circ}\left(167^{\circ}\right.$ at $\mathrm{C} 17$ and $\mathrm{C} 19)$.

For the preparation of "benzologs" of $\mathbf{1 1}$ and $\mathbf{1 2}$ in which an ortho-disubstituted benzene ring has been inserted into one of the butadiyne units, we needed the bisaldehyde 16 (Scheme 5) as the starting material.

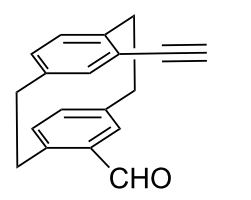

13<smiles>Ic1ccccc1I</smiles>

14

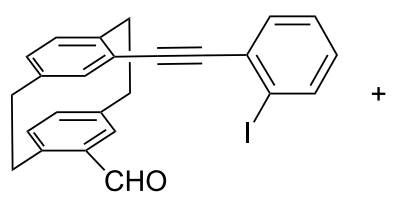

15 (36\%)

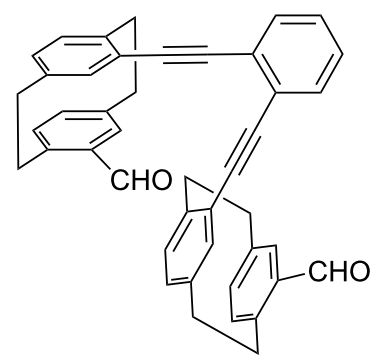

16
$\frac{\mathrm{Pd}\left(\mathrm{PPh}_{3}\right)_{4}, \mathrm{Cul}}{\mathrm{Et}_{3} \mathrm{~N} \text {, toluene, } 20^{\circ} \mathrm{C}}$

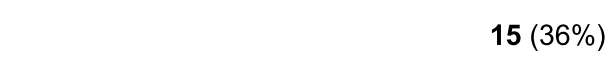

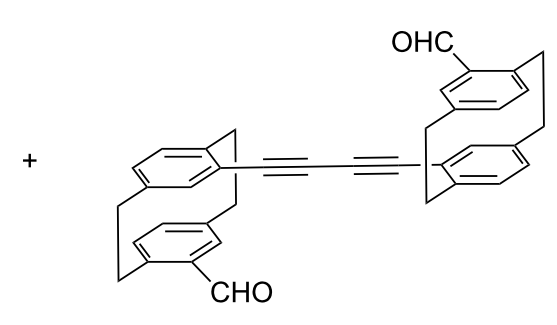


Although its synthesis from the previously described ethynylaldehyde 13 [2,3] appears simple, we always obtained complex mixtures of products when $\mathbf{1 3}$ and excess 1,2-diiodobenzene (14) were subjected to Sonogashira coupling. The main product of this coupling process was the monoaldehyde 15 (i.e., the 1:1coupling product of $\mathbf{1 3}$ and $\mathbf{1 4}$ ). The desired 2:1-product $\mathbf{1 6}$ was always isolated as a side-product together with the dimer of the substrate, dialdehyde 17. Although these two compounds could be separated on a small scale for analytical purposes (see data in Supporting Information File 1) by extensive column chromatography, for further transformations a 16/17 mixture was employed, leaving the ultimate separation/purification to the very end of the synthesis (see Supporting Information File 1).

Having converted 16 by the Bestmann-Ohira transformation [10] into the tetrayne $\mathbf{1 8}$, the stage was set for a final Glaser coupling (Scheme 6).

This provided a mixture of the two hydrocarbons $\mathbf{1 9}$ and $\mathbf{2 0}$ (total yield 78\%) which both could be obtained in pure and crystalline form by repeated chromatography and recrystallization. The final structural proof was again provided by single crystal X-ray analysis (Figure 3 and Figure 4).

Compound 19 (Figure 3) has approximate mirror symmetry (r.m.s.d. $0.12 \AA$ ). The bridges are "parallel", although the angle between the two cyclophane units is ca. $16^{\circ}$ (the average of the

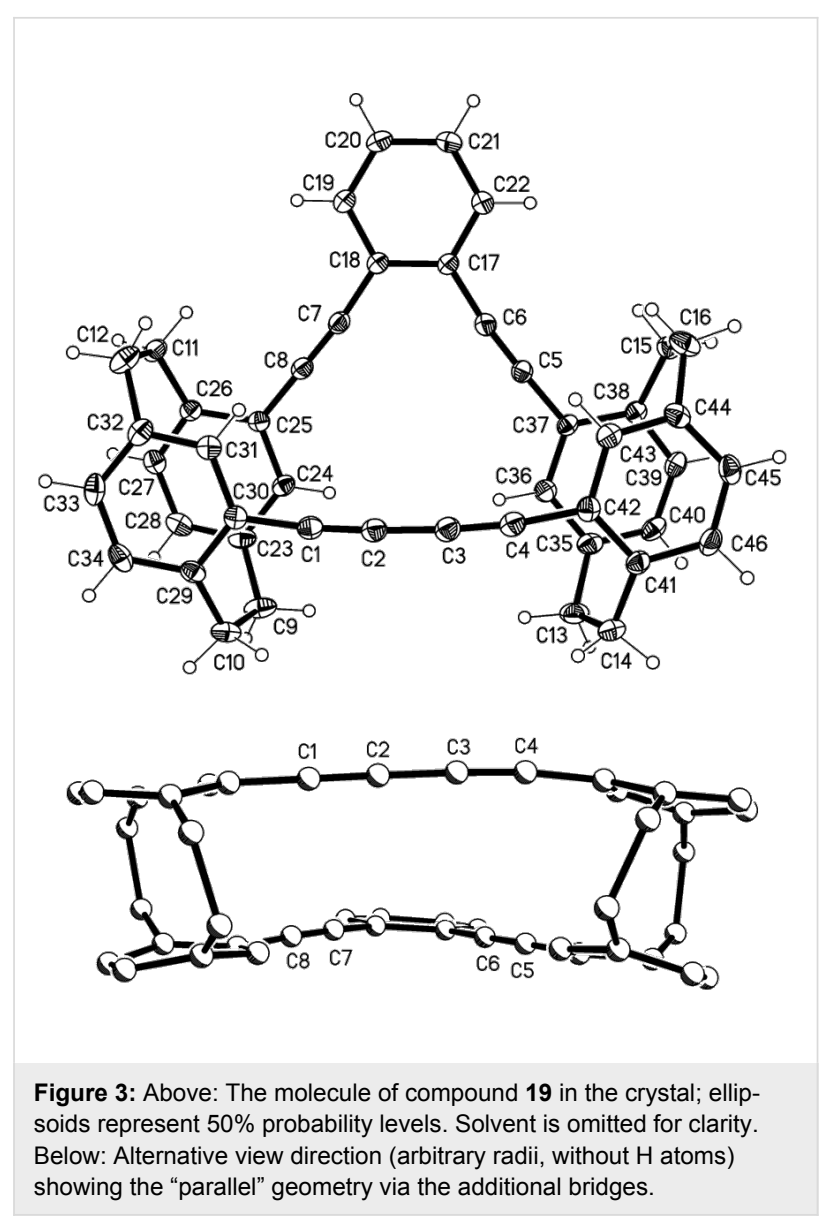

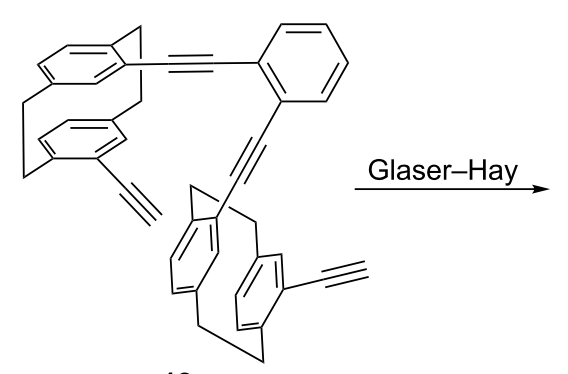

18

(mixture of diastereomers)

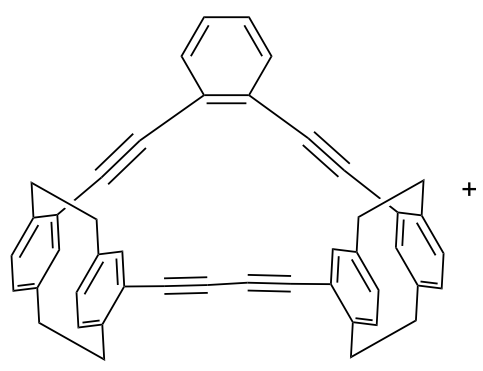

19 (68\%, "parallel")

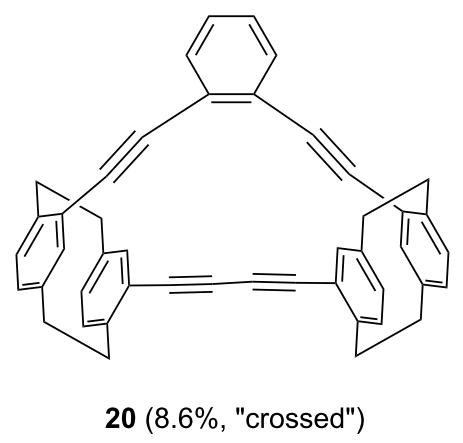

Scheme 6: Preparation of benzologs of dimers 11/12 

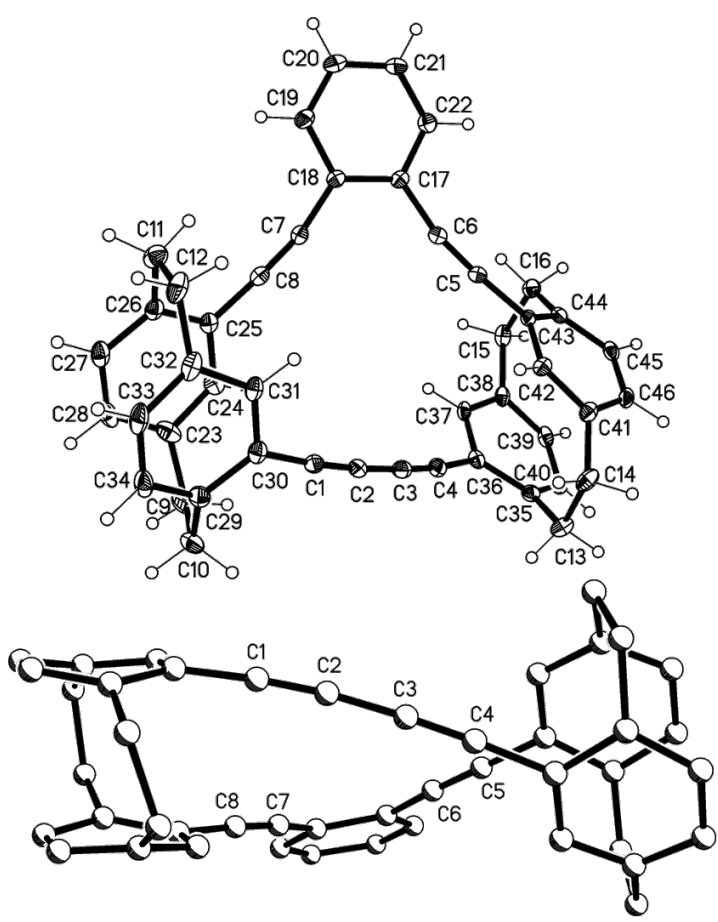

Figure 4: Above: One of the three independent molecules of compound $\mathbf{2 0}$ in the crystal; ellipsoids represent $30 \%$ probability levels. Solvent is omitted for clarity. Below: Alternative view direction (arbitrary radii, without $\mathrm{H}$ atoms) of the same molecule, showing the "crossed" geometry via the additional bridges.

interplanar angles between the two halves across the pseudomirror plane). The two paracyclophane units each show the usual patterns of strain; the twist angles are 1.4 and $4.4^{\circ}$. The eight sp angles are reasonably linear, averaging $175^{\circ}$.

The corresponding "crossed" derivative $\mathbf{2 0}$ crystallizes with three independent molecules, which are reasonably similar (r.m.s.d. of least-squares fits: molecules 1 and 2, $0.19 \AA$; molecules 1 and $3,0.15 \AA$ ), but molecular symmetry within the program tolerance was only found for molecule 1 , which has $C_{2}$ (2) symmetry with an r.m.s.d. of $0.22 \AA$ (Figure 4). The molecules show little strain apart from the standard cyclophane features, with small twist angles of $0.9-4.3^{\circ}$. Exceptions are furnished by the sp angles at $\mathrm{C} 6$ and $\mathrm{C} 7$, which lie in the range $168-170^{\circ}$ for all three molecules; all other sp angles are $172-176^{\circ}$. The angles between the cyclophane units are ca. 61 , $54,57^{\circ}$ for the three independent molecules.

In a final Glaser coupling experiment we wished to crosscouple a representative of either the "flat" series $\mathbf{1 , 3}$, and $\mathbf{5}$ with a representative of the "layered" series $\mathbf{2}, \mathbf{4}$, and $\mathbf{6}$, and for this purpose chose the coupling between $\mathbf{1}$ and $\mathbf{4}$ (Scheme 7).

The desired product $\mathbf{2 2}$ was indeed isolated as the main product ( $45 \%$ ) besides the homo dimer of $\mathbf{1}$, the known [11] tetrayne 21 (32\%). The unambiguous structural proof for 22 was again provided by single-crystal X-ray analysis (Figure 5); all other analytical and spectroscopic data are collected in the experimental section (see Supporting Information File 1).

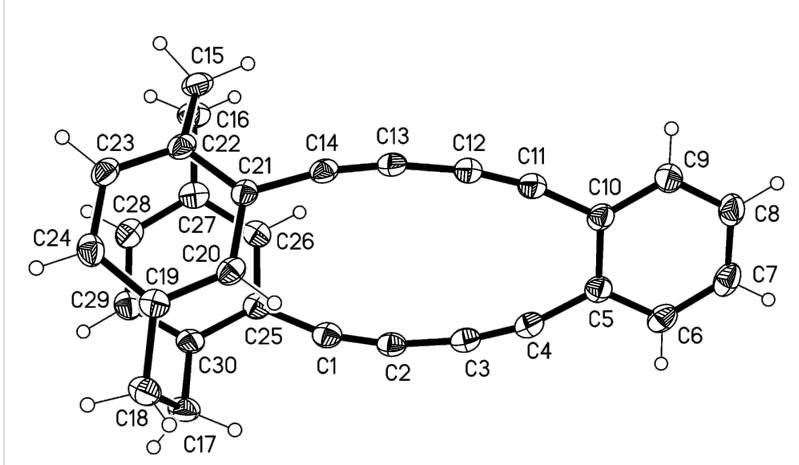

Figure 5: The molecule of compound 22 in the crystal; ellipsoids represent $50 \%$ probability levels.

The "crossed" derivative 22, with its relatively short extra acetylenic bridges and with the clamping effect of the ring $\mathrm{C} 5-\mathrm{C} 10$, is reminiscent of the more strained derivatives presented in the previous paper [1]. The cyclophane rings remain parallel, with a moderate twist angle of $7.8^{\circ}$; they subtend interplanar angles of ca. $40^{\circ}$ with the benzene ring. The strain is again shown in the "soft" sp angles $\left(165-171^{\circ}\right)$ and to some extent in the slightly lengthened $\mathrm{C} \equiv \mathrm{C}$ bonds, $1.21-1.22 \AA$. Perhaps unexpectedly, the main manifestation of strain is to lengthen the aromatic bond $\mathrm{C} 5-\mathrm{C} 10$ to $1.444(3) \AA$, equal in length to the formally single bonds such as $\mathrm{C} 4-\mathrm{C} 5$ that link the acetylenic bridges to the ring systems.

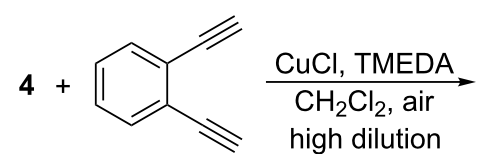

1<smiles>C1#Cc2ccccc2C#CC#Cc2ccccc2C#C1</smiles>

$21(32 \%)$

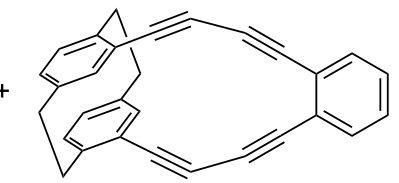

$22(45 \%)$ 
The monoiodide 15, prepared as described in Scheme 5, offers itself for another coupling/cycloisomerization sequence which, in principle, could provide a hybrid molecule consisting of a [2.2]paracyclophane core and a biphenylene bridge, hydrocarbon 27 (Scheme 8).

To prepare this new (and also chiral) cyclophane system we applied the following pathway. Sonogashira coupling of iodide 15 with trimethylsilylacetylene furnished the TMS-protected aldehyde 23 in good yield. Deprotection and conversion of its formyl function into an ethynyl group by the Bestmann-Ohira protocol took place readily and provided the triacetylene $\mathbf{2 4}$, again in good yield (67\%; for the spectroscopic data see Supporting Information File 1). In this intermediate the three triple bonds to be converted into a benzene ring possess only one degree of freedom: the rotation of the non-phane benzene ring around its connecting acetylene group. The cyclotrimerization of three triple bonds under the influence of a cobalt catalyst such as $\mathrm{CpCo}(\mathrm{CO})_{2}$ has been observed many times, notably by the Vollhardt group [12].

In our case, however, the process is not complete. Rather than yielding the expected biphenylenophane 27 , the reaction stops at the stage of the cyclobutadiene complex 26, which is isolated in moderate yield $(40 \%$, Scheme 8$)$. We propose that the cyclization process begins at the two most accessible ethynyl groups of 24, generating the cobaltocyclopentadiene intermediate 25. This cannot proceed to the aromatic ring, since the strain increase associated with the last step is prohibitive. Instead it prefers the isomerization to the isolated CpCo-complex 26.
Compound 26 was identified by its spectroscopic data (see Supporting Information File 1) and also by a single-crystal $\mathrm{X}$-ray analysis. The result is displayed in Figure 6.

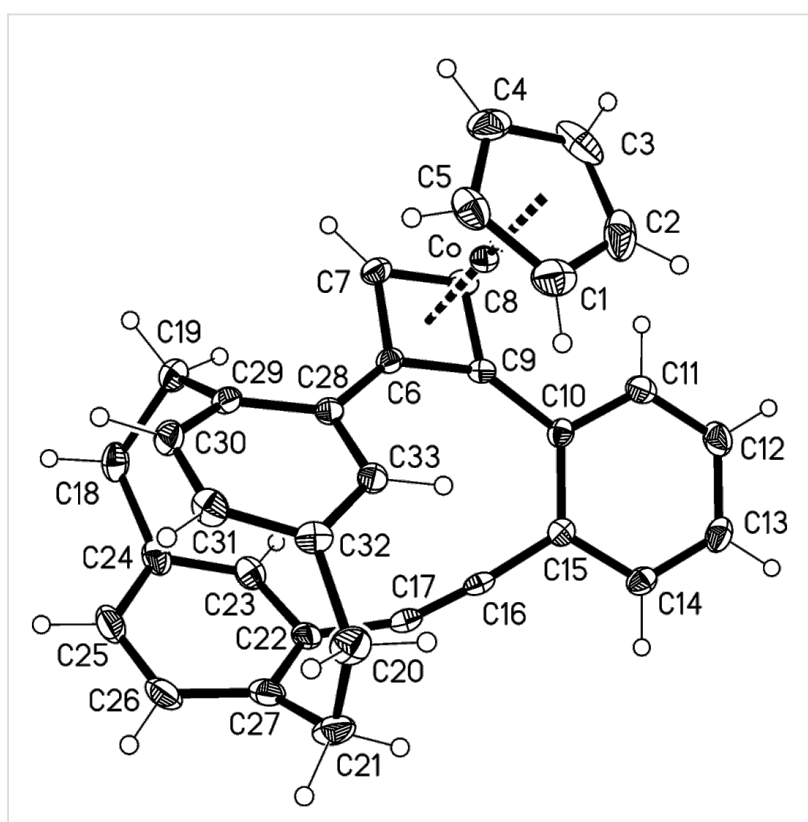

Figure 6: The molecule of compound $\mathbf{2 6}$ in the crystal; ellipsoids represent $50 \%$ probability levels.

The cobalt complex $\mathbf{2 6}$ shows essentially normal geometries for the metal center and the cyclophane systems, although the latter show a twist angle of $9.8^{\circ}$; they are tilted by ca. $45^{\circ}$ with respect to the aromatic ring $\mathrm{C} 10-\mathrm{C} 15$. There is some evidence
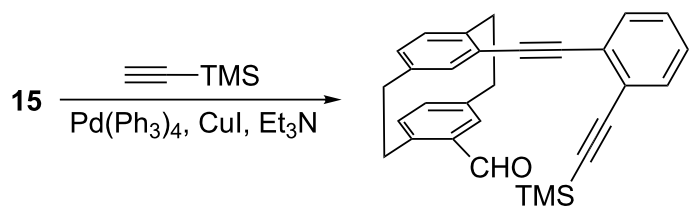

$23(68 \%)$

\section{$\underset{\text { 1. Bestmann-Ohira }}{\stackrel{\mathrm{Cs}_{2} \mathrm{CO}_{3}, \mathrm{MeOH}}{\longrightarrow}}$ $\mathrm{Cs}_{2} \mathrm{CO}_{3}, \mathrm{MeOH}$}

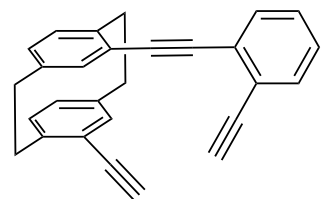

$24(67 \%)$

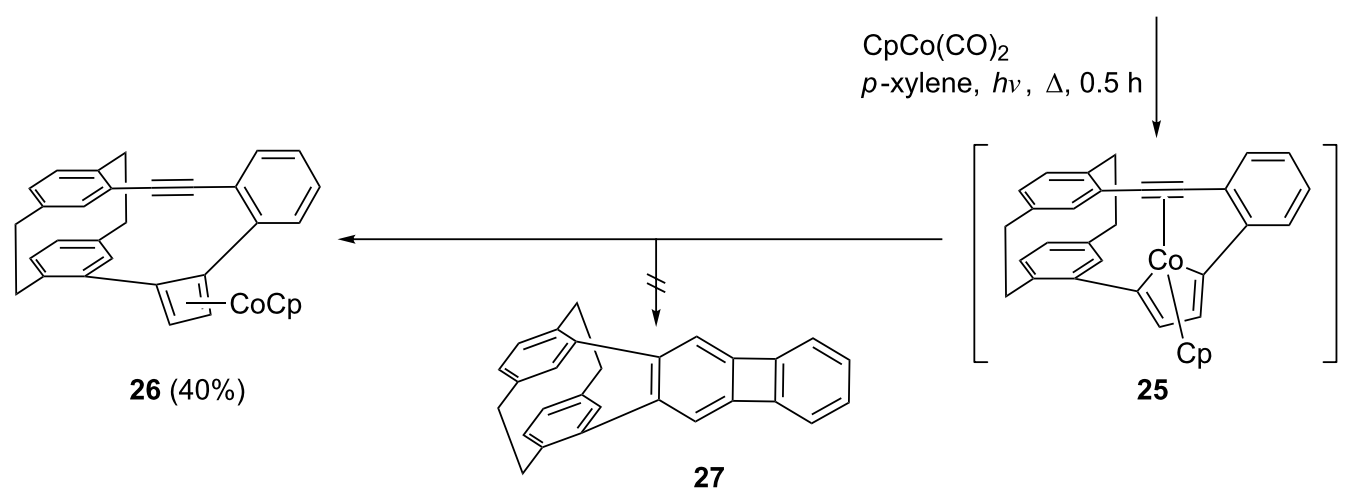

Scheme 8: An attempt to prepare a biphenylenophane. 
of strain in the short bridges between the cyclophanes; thus the bond C6-C9 is at 1.499(2) $\AA$ the longest in the four-membered ring, while the angles at C9 and C6 [144.4(2), 140.0(2); ideally bisecting values would be $\left.135^{\circ}\right]$ are widened and that at $\mathrm{C} 17$, $162.7(2)^{\circ}$, is narrowed. A similar cyclobutadiene complex has been observed by Vollhardt and his co-workers, in a phenylene synthesis in which a planar triacetylene was subjected to $\mathrm{CpCo}(\mathrm{CO})_{2}$-mediated cycloisomerization [13].

\section{Conclusion}

In conclusion, we have considerably extended the range of highly unsaturated carbon scaffolds by using ethynyl[2.2]paracyclophanes as substrates for the generation of new layered frameworks. The above approach is rendered even more attractive by the fact that several of these display interesting stereochemical properties.

\section{Supporting Information}

\section{Supporting Information File 1}

Experimental section.

[http://www.beilstein-journals.org/bjoc/content/ supplementary/1860-5397-10-209-S1.pdf]

\section{Acknowledgements}

We thank Prof. Dr. Y. Okamoto and Dr. M. Girod (University of Nagoya) for carrying out these separation experiments.

\section{References}

1. Dix, I.; Bondarenko, L.; Jones, P. G.; Ernst, L.; Ibrom, K.; Grunenberg, J.; Boese, R.; Hopf, H. Chem. - Eur. J. submitted.

2. Bondarenko, L.; Dix, I.; Hinrichs, H.; Hopf, H. Synthesis 2004, 2751-2759. doi:10.1055/s-2004-834872

3. Hopf, H. Tetrahedron 2008, 64, 11504-11516. doi:10.1016/j.tet.2008.09.048

See for a summary on recent uses of alkynyl cyclophanes for molecular construction.

4. Aly, A. A.; Brown, A. B. Tetrahedron 2009, 65, 8055-8089. doi:10.1016/j.tet.2009.06.034

5. Hopf, H., Ed. Cyclophanes. Isr. J. Chem. 2012, 52, 1-192. doi:10.1002/ijch.201290002 See for a special issue on modern cyclophane chemistry.

6. David, O. R. P. Tetrahedron 2012, 68, 8977-8993. doi:10.1016/j.tet.2012.08.009 See for a recent review on syntheses and applications of disubstituted [2.2]paracyclophanes.

7. Hopf, H. Classics in Hydrocarbon Chemistry; Wiley-VCH: Weinheim, 2000; pp 457-472.

See for a brief summary of the use of $\mathbf{1}, \mathbf{3}$, and $\mathbf{5}$ for the preparation of complex carbon scaffolds.
8. Boydston, A. J.; Bondarenko, L.; Dix, I.; Weakley, T. J. R.; Hopf, H.; Haley, M. M. Angew. Chem. 2001, 113, 3074-3077. doi:10.1002/1521-3757(20010817)113:16<3074::AID-ANGE3074>3.0. CO;2-8

Angew. Chem., Int. Ed. 2001, 40, 2986-2989.

doi:10.1002/1521-3773(20010817)40:16<2986::AID-ANIE2986>3.0.CO ;2-I

9. Hopf, H.; Dix, I.; Raev, V.; Ernst, L. Eur. J. Org. Chem. 2012, 1653-1655. doi:10.1002/ejoc.201101495

10. Patil, U. D. Synlett 2009, 2880-2881. doi:10.1055/s-0029-1218101 And references cited therein.

11. Behr, O. M.; Eglinton, G.; Galbraith, A. R.; Raphael, R. A. J. Chem. Soc. 1960, 3614-3625. doi:10.1039/jr9600003614

12. Vollhardt, K. P. C.; Mohler, D. L. In Advances in Strain in Organic Chemistry; Halton, B., Ed.; JAI: London, 1996; pp 121-160. See for a Review.

13. Baldwin, K. P.; Matzger, A. J.; Scheiman, D. A.; Tessier, C. A.; Vollhardt, K. P. C.; Youngs, W. J. Synlett 1995, 1215-1218. doi:10.1055/s-1995-5247

\section{License and Terms}

This is an Open Access article under the terms of the Creative Commons Attribution License

(http://creativecommons.org/licenses/by/2.0), which permits unrestricted use, distribution, and reproduction in any medium, provided the original work is properly cited.

The license is subject to the Beilstein Journal of Organic Chemistry terms and conditions:

(http://www.beilstein-journals.org/bjoc)

The definitive version of this article is the electronic one which can be found at: doi:10.3762/bjoc. 10.209 